\title{
O espelho do tempo: uma viagem pelas estantes do acervo de obras raras da Biblioteca de Manguinhos
}

\section{Jeorgina Gentil Rodrigues}

\begin{abstract}
Mestre em Ciência da Informação; Bibliotecária; Tecnologista em Saúde Pública da Fundação Oswaldo Cruz; Centro de Informação Científica e Tecnológica; Biblioteca de Manguinhos; Seção de Obras Raras
\end{abstract}

O artigo descreve a formação da coleção de obras raras da Biblioteca de Manguinhos da Fundação Oswaldo Cruz. Foi realizada uma breve análise sobre o conceito de livro raro. Foram feitas recomendações metodológicas visando subsidiar os critérios de raridade bibliográfica.

Palavras-chave: Obra rara; Biblioteca de Manguinhos; Fundação Oswaldo Cruz; Critérios de raridade bibliográfica.

\section{The mirror of the time: a trip for the bookshelves of the rare books of the Manguinhos Library}

The article describes the formation of the rare books collection of Manguinhos Library at Fundação Oswaldo Cruz. This paper briefly conceptualizes what a "rare book" means and the main criteria to consider a given book as rare.

Key-words: Rare book; Manguinhos Library; Oswaldo Cruz Foundation; Criterions of bibliographic rari.

Recebido em 03.05.2007 Aceito em 01.10.2007

\section{Introdução}

Gerar e difundir conhecimento científico e tecnológico. Esse é um dos compromissos da Fundação Oswaldo Cruz (Fiocruz). Nesse contexto, a memória da ciência tem na Instituição um espaço dedicado à sua preservação e valorização. 
A Fiocruz nasceu do Instituto Soroterápico Federal, criado em 25 de maio de 1900 com o objetivo de fabricar soros e vacinas contra a peste. A Biblioteca de Manguinhos foi criada no contexto da fundação do Instituto.

O Instituto, de simples produtor de insumos biológicos, passou a se dedicar também à pesquisa e à medicina experimental, principalmente depois que Oswaldo Cruz assumiu sua direção, em 1902.

A partir de 1902, ao assumir a direção do Instituto, Oswaldo Cruz iniciou a organização da Biblioteca, com a chegada dos primeiros livros e revistas. Eram exemplares variados, sobretudo trazidos da Europa, desde raridades dos séculos anteriores até revistas com as mais recentes descobertas científicas.

No ano de 2006, a Biblioteca de Manguinhos passou a contar com cerca de um milhão de volumes. Em relação ao acervo, 70 mil volumes são considerados raros ou especiais. Especializada em Biomedicina, atende à comunidade científica nacional e oferece suporte ao desenvolvimento da pesquisa e do ensino no âmbito da Fiocruz.

Em 1986, com a criação do então Centro de Informação Científica e Tecnológica (CICT), Unidade Técnico Científica da Fiocruz, a Biblioteca passou a contar com sua atual estrutura, marcando uma nova etapa em sua trajetória histórica.

Na década de 90, a Seção de Obras Raras foi batizada com o nome de Assuerus $\mathrm{H}$. Overmeer, em homenagem ao primeiro bibliotecário da instituição. Encontra-se localizada no $3^{\circ}$ andar do Pavilhão Mourisco, sede original da Biblioteca de Manguinhos. As demais seções da Biblioteca passaram, a partir de 1995, a localizar-se no novo prédio, batizado Pavilhão Haity Moussatché.

A Seção de Obras Raras A. Overmeer possui uma documentação que se estende do século XVII ao século XXI e conta com trabalhos das mais variadas áreas do conhecimento científico, dentre os quais se destacam aqueles realizados nas Ciências Biológicas, na Medicina e na História Natural.

\section{Um pouco de história}

Na seleção de obras clássicas em História Natural, Oswaldo Cruz contou com a colaboração do cientista Arthur Neiva, uma das maiores autoridades em Entomologia do Brasil. Segundo Bustamante (1958, p.12): "Indiscutivelmente, muito se deve a êsse homem, cujo lema era 'simplicidade e bom senso', a eficiência dos serviços da Biblioteca". Formou-se assim, a coleção que originou o embrião do acervo de obras raras.

Intelectual e homem de ação, Oswaldo Cruz sempre afirmou a importância da Biblioteca para os trabalhos do Instituto e garantiu, nos esboços do Pavilhão Mourisco, um espaço ornamentado com detalhes arquitetônicos e decorativos. Conforme Benchimol (1990, p.123):

A biblioteca, especialmente o salão de leitura, é o ambiente de maior riqueza ornamental do pavilhão mourisco. [Transmite] a 
impressão de isolamento do mundo e de elevação espiritual que tão bem se coaduna com aquele lugar de recolhimento e estudo.

Em 1909 Oswaldo Cruz contratou o poliglota Assuerus Hippolytus Overmeer para exercer o cargo de primeiro bibliotecário-chefe da Biblioteca de Manguinhos, onde permaneceu até o ano de sua morte, em 1944.

Em 1913 a Biblioteca passou a ocupar a ala esquerda do 30 pavimento do Pavilhão Mourisco, onde hoje se encontra a Seção de Obras Raras A. Overmeer. As instalações da nova sede correspondiam, na época, a todas as exigências técnicas: pisos de vidro nos armazéns, armações e estantes em aço, iluminadas a eletricidade, com capacidade para 30.000 volumes e amplo salão de leitura.

No ambiente encontram-se móveis em imbuía castanho escuro, luminárias de ferro fundido e bronze, assoalho com desenhos geométricos em diferentes formas e ornamentos em gesso branco nas paredes e no teto.

Com a expansão do acervo, o espaço destinado inicialmente à Biblioteca tornou-se insuficiente para abrigá-lo e para suportar o fluxo de visitantes. Além disso, o peso das coleções de livros e periódicos estava comprometendo a estrutura do prédio. Assim, em 1981, foram transferidas para o Instituto Nacional de Controle de Qualidade em Saúde (INCQS), no campus da Fiocruz, as coleções de periódicos e as obras de referência. Infelizmente, esse espaço não era apropriado para receber tal acervo.

Em 1986, através de um convênio com a Financiadora de Estudos e Projetos (Finep), teve início o projeto de identificação, seleção e tratamento técnico das obras raras da Biblioteca de Manguinhos. 0 projeto viabilizou a contratação de duas bibliotecárias, um auxiliar de biblioteca, uma restauradora e um consultor da área de conservação de acervos documentais. Foram tratados tecnicamente até o término do projeto, em 1992, 1.226 títulos de obras consideradas raras ou especiais, em um universo de oito mil volumes de livros potencialmente raros.

No dia dois de agosto de 1995 foi inaugurado o novo prédio da Biblioteca de Manguinhos, com $5.600 \mathrm{~m}^{2}$ de área útil. O acervo raro permaneceu no Pavilhão Mourisco, marco das origens da Biblioteca. Inicialmente, o prédio havia sido concebido para abrigar o acervo da Biblioteca. Entretanto, outros departamentos do CICT também foram transferidos para o prédio, o que ocasionou uma perda razoável da área destinada ao armazenamento dos periódicos anteriores (conhecida como Armazéns A e B) e do espaço planejado para o crescimento do acervo (reserva técnica).

A iniciativa de difundir digitalmente as obras raras da Instituição iniciou-se em 2000, com a elaboração do 'Projeto Overmeer', que consiste na digitalização do acervo de obras raras da Biblioteca de Manguinhos, visando à sua preservação e disseminação, o que enriquece o patrimônio cultural brasileiro. O projeto recebeu apoio financeiro da Fundação de 
Amparo à Pesquisa do Estado do Rio de Janeiro (Faperj). Os recursos liberados pela Faperj foram utilizados na digitalização de 12 títulos, totalizando 14 volumes, selecionados em um universo de 2.443 títulos já tratados.

O livro na história da humanidade sempre foi um veículo de inovação. Mesmo na era da automação e da busca em base de dados, a importância e utilidade dessas obras raras são inequívocas. Assim, esse acervo interessa diretamente a etólogos, geógrafos, historiadores, biogeógrafos, zoólogos, botânicos, que necessitam, para as pesquisas que desenvolvem, compreender as bases dos códigos internacionais de nomenclatura científica e dos sistemas de classificação utilizados hoje nas Ciências Naturais.

\section{Uma viagem pelas estantes da seção de obras raras}

A Revolução Científica mudou a forma do homem encarar a natureza e gerou a moderna concepção científica. Essa mudança influenciou as grandes navegações empreendidas por Vasco da Gama e Colombo. O resultado dessas viagens foi o conhecimento de um Novo Mundo: as Américas. Ampliou-se o desenvolvimento da História Natural, o que propiciou o conhecimento científico da natureza. A Botânica e a Zoologia, principalmente, evoluíram a ponto de se tornarem disciplinas auxiliares das Ciências médicas. Por exemplo, a flora possibilitou a obtenção de novos recursos para a farmacopéia. Com relação à fauna, se desenvolveram estudos anatômicos, fisiológicos e patológicos, baseados na observação e experimentação, a partir das cuidadosas dissecações de cadáveres de animais.

Os renascentistas viam a obra impressa como algo mais do que a simples comunicação de uma nova descoberta científica: ela se constituía em um instrumento indispensável à prática e à pesquisa, podendo-se comparar sua importância, na atualidade, com a do computador ou a do microscópio. Para Ziman (1981, p.111): "A coincidência da ascensão da Ciência com o descobrimento da imprensa não foi de modo algum um mero acidente".

O estudo da Medicina Tropical, com a descrição das doenças brasileiras, foi inaugurado sob o domínio holandês, com o médico Willem Piso e o naturalista Georg Marggraf. Piso e Marggraf também deixaram importantes registros sobre a história natural do Nordeste. Em 1648 publicaram a obra Historia Naturalis Brasiliae. Esta obra também serviu de fonte para a inclusão das espécies da fauna e da flora brasileiras no Systema Naturae (1758-59) de Carl von Linné. Entre os itens do acervo da Biblioteca de Manguinhos, encontram-se estas magníficas obras.

No curto período em que Villegaignon ocupou o território brasileiro (1557-1558), o missionário Jean de Léry editou, em 1578, a Histoire d'un Voyage faict en la terre du Brésil, onde apresentou a descrição do país, da língua e dos costumes indígenas e da relação destes com os europeus. A Biblioteca de Manguinhos possui a edição de 1874, quando de sua publicação em território brasileiro. 
Ressaltam-se alguns trabalhos importantes para 0 advento da ciência: Experimenta circa generation insectorum (1671), do médico e biólogo italiano Francesco Redi, considerado um dos fundadores da Biologia Experimental; e Systema Entomologiae, sistens, Insectorum classes, ordines, genera, species (1775), do entomologista dinamarquês Johann Christian Fabricius, que elaborou princípios teóricos avançados para a época, como o de que novas espécies poderiam surgir por hibridização e pela influência do meio-ambiente sobre a estrutura anatômica e funções orgânicas.

Com o apoio do Estado Português, o naturalista baiano Alexandre Rodrigues Ferreira descreve plantas, animais, regiões e aspectos físicos e culturais das populações indígenas do interior do Brasil. Ferreira chefiou a chamada Viagem Filosófica pela Amazônia e Mato-Grosso, expedição encarregada de fazer levantamentos das riquezas naturais do Brasil, nas capitanias do Grão-Pará, Rio Negro, Mato Grosso e Cuiabá, que durou dez anos, de 1783 a 1793. A partir da Viagem Filosófica, a Amazônia tornouse palco de inúmeras outras expedições de naturalistas estrangeiros interessados em seu conhecimento. A importância desta obra só recentemente foi reconhecida. Dentre as edições existentes, a Biblioteca de Manguinhos possui a do material iconográfico de 1971, do Conselho Federal de Cultura. Dos cinco volumes programados, só foram publicados dois: um de Geografia e Antropologia e um de Zoologia.

Os livros raros podem recriar o passado ou criar um novo cenário. Por exemplo, o Erario Mineral (1735) do médico português Luís Gomes Ferreira, curioso documento para a História da Medicina, constitui um dos melhores tratados sobre a Patologia e a Terapêutica do Brasil Colonial. A obra Ornitologia brasileira (1944), do naturalista Jean Théodore Descourtilz, traçou com fidelidade um quadro ecológico do Brasil, na introdução da edição original, publicada em 1852, em Paris.

A relação de obras editadas no século XVIII é bastante rica. Nesse século surgiram os códigos internacionais de nomenclatura científica da Química, da Zoologia e da Botânica. Nesse sentido, destacam-se os livros de Pier Antonio Micheli, Karl de Geer, Johann Christian Fabricius, Mark Catesby, Carl von Linné e Jean Baptiste Antoine de Monet de Lamarck. Esses autores e suas obras enriquecem o acervo da Biblioteca de Manguinhos.

Em relação a esses autores, destaca-se a obra taxionômica de Linné e as contribuições de Lamarck, que criou o termo 'biologia' e propôs a primeira teoria científica da evolução das espécies, mais tarde desenvolvida e reformulada por Darwin.

$O$ estudo dos textos originais é essencial para os historiadores. Até o final do século XVIII algumas epidemias como a malária, a varíola, a febre amarela e o sarampo, assolaram alguns núcleos urbanos atingindo principalmente os índios. No acervo destaca-se um manuscrito jesuíta do ano de 1703 , que contém a descrição de várias ervas e receitas utilizadas na terapêutica das doenças que acometiam os habitantes da colônia brasileira. 
Do século XVIII encontra-se também no acervo o trabalho do Frei José Mariano da Conceição Veloso, naturalista brasileiro, reconhecido como o "pai da Botânica brasileira". Suas viagens pelo Rio de Janeiro, promovidas pelo vice-rei $\mathrm{D}$. Luís de Vasconcelos, se deram entre 1782 e 1790. Veloso tinha por objetivo realizar o levantamento dos recursos naturais da capitania do Rio de Janeiro. Apesar do rigor científico na elaboração do material produzido, a divulgação dos resultados da viagem foi demorada e incompleta. A Flora Fluminensis foi publicada em oito volumes in-fólio entre 1827 e 1835.

O século XIX foi marcado pela vinda da Família Real de Portugal para o Brasil. Como conseqüência, abriram-se os portos, criou-se a imprensa e fundaram-se instituições de ensino e de pesquisa que perduram até nossos dias. A exploração científica da América do Sul iniciada por Humboldt ganhou impulso com a abertura dos portos. As grandes expedições que revelaram a riqueza da flora e da fauna brasileiras e seus padrões biogeográficos contribuíram para a revolução dos conceitos e teorias vigentes.

Assim, essas obras científicas descrevem, por meio de textos e ilustrações, seres humanos, animais, plantas e o meio-ambiente onde se encontravam representados. Entre os itens do acervo, encontram-se as mais importantes publicações de naturalistas-viajantes que estiveram no Brasil no século XIX, como: Alexander von Humboldt, Maximilian von Wied-Neuwied, Auguste de Saint Hilaire, Karl Friedrick Philipp von Martius, Johann Baptiste von Spix, Hermann Burmeister, Louis Agassiz e Elizabeth Cabot Agassiz e também François Auguste Biard.

Ressaltam-se ainda no acervo obras como Travels in the interior of Brazil etc. (1816), do mineralogista inglês John Mawe, primeiro estrangeiro a receber permissão do Príncipe Regente para viajar pelo interior das Minas Gerais, de onde se extraíam pedras preciosas; e Travels in Brazil (1818), do escritor inglês Henry Koster, obra clássica sobre o Nordeste Brasileiro.

Com a Independência, em 1822, se seguiu um período de lutas contra a reação portuguesa, guerras e dissensões internas. Por este motivo houve poucas iniciativas na área cultural e científica no Primeiro Império.

No Segundo Império D. Pedro II destacou-se pelo incentivo às artes e às ciências. De acordo com Schwartzman (1979, p.57): "O Brasil [...] teve a felicidade de contar com um imperador que era cientista amador, e a isso se credita grande parte do que foi possível fazer na área científica [...]". Ainda no século XIX ganharam repercussão as teorias 'polêmicas' do naturalista inglês Charles Darwin, no meio científico de sua época. Em 1859 Darwin publicou a obra The Origin of Species, teoria científica sobre a evolução das espécies. Entre os itens do acervo, a Biblioteca possui a edição de 1862, além de outras obras do autor.

A partir de 1870 inicia-se no Brasil uma série de mudanças sociais e políticas. Segue-se o colapso da Monarquia, o exílio de D. Pedro II e a Proclamação da República, em 1889. 
No início do século XX o então Instituto Oswaldo Cruz, hoje Fiocruz, promoveu expedições científicas em apoio às atividades da Estrada de Ferro Central do Brasil e da Estrada de Ferro Madeira-Marmoré, entre outras. Quando desenvolvia atividades referentes à profilaxia da malária, em um trecho da Estrada de Ferro Central do Brasil, Carlos Chagas identificou o ciclo da transmissão da doença que leva seu nome. Estudo esse que permanece como um marco de afirmação da ciência nacional.

Em 1912 foi divulgado o relatório da expedição científica liderada pelos médicos Belisário Penna e Arthur Neiva, que contribuíram para a caracterização do quadro de doenças e das condições de vida das populações do interior do Nordeste e do Centro-Oeste.

Entre os itens do acervo, encontra-se o relatório Madeira-Marmoré Railway Company (1910), do sanitarista brasileiro Oswaldo Cruz. A importante expedição de Penna e Neiva foi publicada como artigo nas Memórias do Instituto Oswaldo Cruz (1916, t.8, fasc. 3). A Biblioteca possui a coleção completa das Memórias.

A Biblioteca de Manguinhos tem ainda em seu acervo grande parte da 'Coleção Brasiliana', publicada pela Companhia Editora Nacional de 1931 a 1980. A coleção completa é composta de 387 títulos. Essa coleção é considerada o mais completo repositório de informações sobre o Brasil, suas origens, sua formação, sua vida em todos os campos do conhecimento humano. A Biblioteca possui títulos como: Tratado descritivo do Brasil em 1587, de Gabriel Soares de Souza (v. 117); Tratados da Terra e Gente do Brasil, de Fernão Cardim (v.168); Singularidades da França Antártica, de André Thevet (v.229), entre outros.

A formação da coleção de teses iniciou-se quando Oswaldo Cruz criou, em 1908, os "Cursos de Aplicação" de Manguinhos. Com a notoriedade da Instituição, pesquisadores, especialistas e técnicos brasileiros e de outros países colaboraram para a formação dessa coleção, doando seus trabalhos acadêmicos. Entre as teses encontradas em nosso acervo destacam-se: Estudos hematológicos no impaludismo, de 1903, do pesquisador Carlos Chagas, que conquistou a cátedra da especialidade na então Faculdade Nacional de Medicina, atual Universidade Federal do Rio de Janeiro.

Conforme Ávila-Pires (1993), Oswaldo Cruz também se preocupou com as inter-relações do homem com a flora, fauna, clima, solo, água e ar. Em sua tese inaugural, A veiculação microbiana pelas águas (1893), nota-se uma noção nítida de diversos conceitos só recentemente consagrados pela ecologia. A Biblioteca possui um exemplar de sua tese.

Além disso, a Biblioteca possui 601 títulos de revistas científicas internacionais e nacionais consideradas raras. Estão guardados nesse conjunto importantes periódicos brasileiros do século XIX e XX. Destacamse o Brasil-Médico (Rio de Janeiro, 1877-1971), a Gazeta Médica da Bahia (Bahia, 1876-1972), A Tribuna Médica (Rio de Janeiro, 1899-1972), a Revista do Instituto Histórico e Geográfico (Rio de Janeiro, 1839-1929), os Anais da Academia Nacional de Medicina do Rio de Janeiro (Rio de Janeiro, desde 1885), as Memórias do Instituto Oswaldo Cruz (Rio de Janeiro, 
desde 1909), títulos fundamentais para o processo de constituição e de consolidação da imprensa científica e cultural no Brasil.

Em relação aos periódicos raros estrangeiros, destacam-se: Annales de Chimie et de Physique (Paris, 1789-1913), Annalen der Physick (Leipzig, 1790-1983), Journal D'Hygiene (Paris, 1910-1913), Proceedings of the Royal Society of London (1800-1969) e American Journal of Medicinal Science (1891- 1997). Encontram-se também títulos ainda correntes: Lancet (Londres, desde 1823), Nature (Londres, desde 1892), Journal of Experimental Medicine (New York, desde 1896) e Science (Washington, desde 1900).

\section{0 que é obra rara?}

Para que ao livro seja atribuído o qualificativo de raro, deve-se considerar não apenas a sua beleza tipográfica, antigüidade, unicidade ou valor comercial, mas também o seu considerável potencial de informação.

A expressão "livro raro" tem diversos atributos - a excelência literária, a perfeição tipográfica, a procedência, o conteúdo, entre outros dependendo do sentido em que é empregada.

$\mathrm{Na}$ literatura consultada observou-se que os conceitos de raridade são, usualmente, baseados no consenso geral do "velho-antigo-preciosoraro". Entretanto, um livro pode ser considerado raro ao sair do prelo. Horch (1982, p.63), quando trata do livro raro, faz a seguinte observação sobre o significado da palavra raro e sua relação com o livro: "Em relação ao livro, o fator raridade é importante ou, mesmo, primordial. No entanto, não é exclusivo. Existem vários fatores, para que ao livro seja atribuído o qualificativo raro".

Com isso, considerou-se que a determinação de critérios para a qualificação de obras raras deve responder às seguintes questões:

- Com que finalidade? (critérios objetivos);

- A quem interessa? (critérios subjetivos).

Partindo dessa premissa, o bibliotecário deve avaliar o acervo considerado "raro", face à importância deste para a instituição, por constituir parte de sua história, pelo valor histórico ou comercial (critérios objetivos) e seu conseqüente valor bibliográfico ou bibliológico para o usuário (critérios subjetivos). Só depois da avaliação do acervo é que o bibliotecário pode definir critérios de raridade bibliográfica.

\section{Critérios de raridade relativa}

Pinheiro (1989, p.21) entende que a identificação de critérios de raridade bibliográfica "implica na abordagem do caráter bibliológico das obras e na ênfase da influência social, econômica, e cultural, sofrida por todas as autoridades que contribuíram na elaboração física e intelectual de uma obra". 
O critério da raridade relativa pode levar a considerar um livro como raro, dependendo de determinadas características: uma edição com alguma particularidade ou caráter próprio que a distinga das demais; a relevância histórica da obra; uma edição que testemunhe os estágios de avanços científicos e tecnológicos; uma obra representativa do escopo da instituição em que está localizada; um exemplar acrescido de elementos em período posterior à sua publicação, por exemplo, autografado pelos autores ou personalidades de renome.

Esses critérios podem ser sistematizados e aplicados às mais diversas circunstâncias. Como exemplo, podemos citar os seguintes catálogos de obras raras que consideraram o aspecto do valor cultural na seleção e formação de seu acervo raro:

[...] produções literárias e scientíficas dos melhores poetas [...] tanto nacionais como estrangeiros, dadas à luz pelos prelos de todo mundo desde meados do século XV até nossos dias [...] (SANTOS, 1921-1922, pt.1, p.7);

[...] obras que devem figurar [...] como marcos sempre vivos da linguagem, do espírito e dos hábitos de uma época (BIBLIOTECA PÚBLICA DO ESTADO, 1972, p. [iii]);

[...] coletânea de interesse em diversas fases da cultura pernambucana [...] (ARQUIVO PÚBLICO ESTADUAL, 1982, p.6);

[...] ao conteúdo que encerram e às circunstâncias de onde emergiram [...] (BIBLIOTECA RIO GRANDENSE, 1986, p.5);

[...] obras representativas que retratam o Brasil na visão dos viajantes que descreveram seus habitantes, doenças e tratamentos, geografia animais e plantas (BIBLIOTECA DE MANGUINHOS, 1992, texto da orelha).

Os códigos de catalogação especializados adotam tanto o limite histórico como as características das obras produzidas artesanalmente (independente da época de publicação) como critérios básicos, na seleção e formação de um acervo considerado raro:

[...] monografias impressas editadas antes de 1801 , e [...] publicações posteriores editores editadas artesanalmente, ou por processos que perpetuam a tradição do livro artesanal [...] (FEDERAÇÃO INTERNACIONAL DAS ASSOCIAÇÕES DE BIBLIOTECÁRIOS E DAS BIBLIOTECAS, 1985, p.1);

[...] publicações produzidas antes da introdução da mecanização da imprensa no século XIX [...]" (ESTADOS UNIDOS, 1991, p.1, tradução nossa).

As fontes de informação comerciais também utilizam o critério da raridade relativa. Os livreiros, para valorizar determinado exemplar, utilizam termos como 'obra rara', 'extremamente rara', 'muito rara' ou 
'raríssima' e 'obra esgotada', não existindo um conceito definido para cada termo.

Pinheiro (1989, p.12) observa que: "[...] nas fontes de informação comerciais, que vão avaliar, em espécie, cada unidade bibliográfica - o preço passa a ser indicador de 'raridade' ".

O critério da raridade relativa também é adotado por bibliófilos e bibliógrafos, que podem considerar como "rara": uma primeira edição, um exemplar pouco conhecido, uma edição premiada, um fac-símile, uma encadernação de luxo, uma obra com estampas originais. Segundo Cunha (1984, f.[1]):

Deve-se ponderar que, conforme interesses específicos de bibliotecas e/ou colecionadores, outros critérios podem ser acrescidos. Entretanto a classificação de qualquer obra dentro destes padrões exige um apoio bibliográfico i.e., consultas a bibliografias, catálogos especiais com descrição de exemplares, conhecimento de história do livro e outras fontes de informação e referência.

Sem dúvida há vários critérios para qualificar um livro como raro e há várias categorias de livros raros. Contudo, a raridade relativa não contraria o caráter de raridade internacional de uma obra. Neste contexto, quais são os critérios empregados para qualificar uma obra como rara, internacionalmente?

Cunha (1984, f.[1]) elaborou os seguintes critérios para a qualificação de obras raras adotados pela Fundação Biblioteca Nacional:

- Primeiras impressões (séc. XV - XVI)

- Impressões dos séculos XVII e XVIII (até 1720)

- Edições de tiragens reduzidas

- Edições especiais (de luxo para bibliófilos)

- Edições clandestinas

- Obras esgotadas

- Exemplares de coleções especiais (regra geral com belas encadernações e ex-libris)

- Exemplares com anotações manuscritas importantes (incluindo as dedicatórias) [...].

Conforme interesses específicos de bibliotecas, outros critérios podem ser acrescidos. Entretanto, a classificação de qualquer obra dentro destes padrões exige um apoio bibliográfico, ou seja, consultas a bibliografias, catálogos especiais com descrição de exemplares, conhecimento da história do livro e outras fontes de informação e referência.

O livro raro se impõe hoje como objeto de reflexão (história e memória) e de desenvolvimento dos estudos a respeito dele e das instituições responsáveis por sua guarda e divulgação. 
A atribuição de valores depende das competências ou das expectativas dos diferentes usuários. Por exemplo, o historiador atribui valor de registro de conhecimento; o cientista da informação atribui valor de registro de informação.

\section{Critérios de qualificação de obras raras e especiais da Biblioteca de Manguinhos}

A Biblioteca de Manguinhos desenvolveu os seguintes critérios de raridade bibliográfica (BIBLIOTECA, 1992, p.[23]-24):

Obras Raras e Especiais:

- Obras publicadas até o Século XVIII (o fator data impõe-se naturalmente);

- Obras publicadas no Brasil no Século XIX (período-marco, com a instalação da tipografia no Brasil em 1808);

- Livros com estampas originais (ilustrações de artistas de renome ou dos próprios autores);

- Trabalhos que sejam marcos para o progresso da Ciência (como as edições antigas da História Natural de Linné, primeiro a criar um sistema internacional de nomenclatura zoológica e botânica);

- Trabalhos que sejam marcos na História Científica do Brasil (como Flora Brasiliensis, de von Martius);

- Obras esgotadas;

- Livros de valor científico editados até o final do Século XIX;

- Edições clandestinas;

- Edições especiais (definem-se por si só e são importantes porque restritas em sua destinação e seu objetivo).

Exemplares Raros e Especiais:

- Com dedicatória manuscrita dos autores e/ou personalidades de renome;

- Autografados pelo(s) autor(es);

- Com marcas de propriedade (assinaturas, ex-libris, carimbos, brasões etc.);

Com tiragem especial em edições comuns.

\section{Considerações finais}

Avaliar o potencial de uma obra rara é tarefa que requer estudo constante e reavaliação periódica. Faz-se necessária sua inserção em um contexto histórico específico, não apenas como produto dele, mas como algo que nesse mesmo contexto interfere. 
Para Moraes (1998, p.21): "Todo livro que cita pela primeira vez um fato importante, marca uma data na História, tem um valor bibliográfico universal, é procurado e se torna geralmente raro". As características históricas de determinada época são o resultado de um contínuo processo de transformação. As obras que naquele momento são produzidas também estão sujeitas a este processo. Então, entender a obra rara é estudá-la em sua historicidade, apresentando seu significado em cada momento, chegando a seu significado atual.

Diante deste quadro, essencialmente subjetivo, como caracterizar uma obra como rara? Certamente seria a mesma coisa que caracterizar um vinho como de qualidade excepcional, um castelo em ruínas ou uma esmeralda. Todos têm o seu valor, intrínseco ou extrínseco. Cabe ao usuário, ao pesquisador da obra, sua avaliação.

A mudança do paradigma da informação trazida pela inovação científica e tecnológica acarretou um novo olhar sobre o papel que essas obras têm no desenvolvimento da Ciência. Por tudo isso, a Fiocruz tem a responsabilidade de preservar esse acervo e criar as condições necessárias para o seu aproveitamento.

Neste contexto, o acervo de obras raras da Biblioteca de Manguinhos fornece subsídios que podem ser considerados como fonte fomentadora de novos conhecimentos para a história natural, história da medicina, saúde pública e saneamento.

Através do livro raro é possível estudar a gênese das principais teorias do saber contemporâneo e descobrir como esses 'saberes' surgiram e que tipo de relações existiam entre esses 'saberes' e os intelectuais que os propuseram no contexto das sociedades da época.

Conclui-se, portanto, que o livro raro pode servir como um espelho do tempo para a pesquisa científica, ao mostrar a relatividade dos conceitos utilizados em cada época histórica. Os próprios conteúdos evidenciam as linhas de pesquisas que deixaram de ser exploradas e que poderiam se revelar fecundas; ou que se transformaram com o decorrer dos anos.

\section{Referências}

ARQUIVO PÚBLICO ESTADUAL (DE PERNAMBUCO). Catálogo de folhetos raros, I (000/200). Recife: Arquivo Público Estadual de Pernambuco, 1982.

BENCHIMOL, J. L. (Coord.). Manguinhos de sonho à vida: a ciência da Belle époque. Rio de Janeiro: COC, 1990.

BIBLIOTECA DE MANGUINHOS. Catálogo de obras raras e especiais da Biblioteca de Manguinhos. Rio de Janeiro: Fiocruz, 1992.

BIBLIOTECA PÚBLICA DO ESTADO [DO RIO GRANDE DO SUL]. Catálogo de obras raras ou valiosas da Biblioteca Pública do Estado. Porto Alegre: Globo, 1972. 
BIBLIOTECA RIO-GRANDENSE. Levantamento bibliográfico parcial de obras raras e/ou valiosas da Biblioteca Rio Grandense. Rio Grande: Ed. da UFRG, 1987.

BUSTAMANTE, E. As bibliotecas especializadas como fonte de orientação na pesquisa científica. Rio de Janeiro: Instituto Oswaldo Cruz, 1958.

CUNHA, L. da F. F. da. Critérios empregados para qualificação de obras raras [Rio de Janeiro: Biblioteca Nacional], 1984. datil.

ESTADOS UNIDOS. Library of Congress. Office Descriptive Cataloging Policy. Bibliographic description of rare books. Washington, D.C.: LC, 1991.

FEDERAÇÃO INTERNACIONAL DAS ASSOCIAÇÕES DE BIBLIOTECÁRIOS E DAS BIBLIOTECAS. ISBD (A), descrição bibliográfica internacional normalizada de monografias antigas. Lisboa: Instituto Português do Patrimônio Cultural, 1985.

HORCH, R. E. O livro raro no Brasil. Comunicações e Artes, São Paulo n.11, p.63-71, 1982.

LE GOFF, J. História e memória. 2.ed. Campinas: Ed. UNICAMP, 1992.

MORAES, R. B. O bibliófilo aprendiz. 3. ed. Brasília: Briquet de Lemos, 1998.

PINHEIRO, A. V. Que é livro raro?: uma metodologia para o estabelecimento de critérios de raridade bibliográfica. Rio de Janeiro: Presença, 1989.

SANTOS, J. (Comp.) Catálogo da importante e preciosissima livraria que pertenceu aos... Condes de Azevedo e de Samodães... Porto: Typ. Da Empresa Litteraria e Typographica, 1921-192 2 pt.

SCHWARTZMAN, S. Ciência, universidade e ideologia, a política do conhecimento. Rio de Janeiro: Zahar, 1981.

ZIMAN, J. A força do conhecimento, a dimensão científica da sociedade. São Paulo: EDUSP, 1981.

\section{Bibliografia Complementar}

AVILA-PIRES, F. D. ; ARAGÃO, M. B. (org.). A ecologia na primeira metade do século $X X$. Rio de Janeiro: ENSP, 1993, p. 9-19.

AZEVEDO, F. (org.). As Ciências no Brasil. 2.ed. Rio de Janeiro : Ed. UfRJ, 1994. 2

CHARTIER, R. A ordem dos livros, leitores, autores e bibliotecas na Europa entre os séculos XIV e XVIII. Brasília: Ed. UnB, 1994.

CHILDE, G. A evolução cultural do homem. Rio de Janeiro: Zahar, 1966.

ESCARPIT, R. A revolução do livro. Rio de Janeiro: FGV, 1976.

FEBVRE, L. ; MARTIN, H.-J. O aparecimento do livro. São Paulo: Ed. UNESP, 1992. 
FONSECA FILHO, O. da. A escola de Manguinhos, contribuição para o estudo do desenvolvimento da medicina experimental no Brasil. São Paulo, Revista do Tribunais, 1974. Separata do T.2 de "Oswaldo Cruz Monumenta Histórica".

FONSECA FILHO, O. da. Oswaldo Cruz e a pesquisa científica no Brasil. Bol. Acad. Nac. Med., Rio de Janeiro, v.144, p.8-22, 1972. Suplemento.

FOUCAULT, M. A arqueologia do saber. 2.ed. Rio de Janeiro: ForenseUniversitária, 1986.

FOUREZ, G. A construção das ciências: introdução a filosofia e à Ética das ciências. São Paulo: Ed. UNESP, 1995.

FRIEDMANN, L. M. História da Biblioteca de Manguinhos. Rio de Janeiro, 1991. mimeo.

GRUPO de Estudos em Obras Raras do Rio de Janeiro. Segurança em acervos raros. Rio de Janeiro: Fundação Biblioteca Nacional, 1994. p.1112.

LE GOFF, J. História e memória. 2.ed. Campinas: Ed. UNICAMP, 1992.

MORAES, R. B. O bibliófilo aprendiz. 3. ed. Brasília: Briquet de Lemos, 1998.

MORAES, R. B. Bibliografia brasileira do período colonial. São Paulo: Instituto de Estudos Brasileiros, 1969.

MORAES, R. B. Livros e bibliotecas no Brasil colonial. Rio de Janeiro, Livros Técnico e Científicos. São Paulo: Secretaria de Cultura, Ciência e Tecnologia do estado, 1979.

MORAES, R. B.; BERRIEN, W. Manual bibliográfico de estudos brasileiros. Rio de Janeiro: Gráfica Editora Souza, 1949. p. 592-627.

MOREL, R. L. M. Ciência e estado, a política científica no Brasil. São Paulo: T. A. Queiroz, 1979.

MOTOYOMA, S. Ciência e tecnologia e a história da dependência do Brasil. Rev. Bras. Tecnol. Brasília, v.15, n.3, p.5-17, maio-jun. 1984.

NEIVA, A. Esboço histórico sobre a botânica e zoologia no Brasil. [2.ed.] Brasília: Ed. UnB, 1989.

OLIVEIRA, J. T. A fascinante história do livro. Rio de Janeiro. Rio de Janeiro: Kosmos, 1989.

PINHEIRO, A. V. A Biblioteconomia de Livros Raros no Brasil, necessidades, problemas e propostas. Rev. Bibliotecon. Comun., Porto Alegre, v.5, p.41-44, jan./dez., 1990.

RIZZINI, C. A. O livro, o jornal e a tipografia no Brasil: 1500 -1822. Rio de Janeiro: Kosmos, 1946.

RODRIGUES, J. G. Espelho do tempo: análise da coleção de obras raras da Fundação Oswaldo como fonte de pesquisa para Ciência Moderna. Rio de 
Janeiro, 1996. Dissertação (Mestrado em Ciência da Informação) Universidade Federal do Rio de Janeiro, em convênio com o IBICT.

SANTANNA, V. M. Ciência e sociedade no Brasil. São Paulo: Símbolo, 1978.

STEPAN, N. Gênese e evolução da ciência brasileira, Oswaldo Cruz e a política de investigação científica e médica. Rio de Janeiro: Fundação Oswaldo Cruz, 1976.

UNIVERSIDADE FEDERAL FLUMINENSE. Núcleo de Documentação. Documentos raros e/ou valiosos, critérios de seleção e conservação. Niterói: Núcleo de Documentação da UFF, 1987. 